\title{
TRANSITAR PARA ONDE? MONSTRUOSIDADE, (DES)PATOLOGIZAÇÃO, (IN)SEGURANÇA SOCIAL E IDENTIDADES TRANSGÊNERAS
}

\author{
Jorge Leite Junior \\ Universidade Federal de São Carlos
}

\begin{abstract}
Resumo: O objetivo deste artigo é discutir a categoria "monstro" e sua íntima relação com a patologização e/ou criminalização de determinadas pessoas vistas como 'desviantes sexuais', em especial travestis, transexuais e intersexuais. No início do século XXI, com o questionamento da autoridade médica, a politização dos movimentos sociais de travestis e transexuais e a batalha por sua despatologização, para onde se encaminham os "transtornos" de sexo ou gênero, as "parafilias" e as "perversões" com toda a persistente estigmatização a elas referidas? Voltarão a ser redimensionadas como algo potencialmente perigoso através da cada vez mais abrangente cultura da segurança?

Palavras-chave: monstro; abjeto; travestis; transexuais; ciência sexual.
\end{abstract}

"É o inumano, o que está além do humano, o que é menos que humano, o limite que garante ao humano sua ostensiva realidade." Judith BUTLER, 2006, p. 307

"O monstro humano combina o impossível e o interdito." Michel FOUCAULT, 1997, p. 61

"O pseudo-hermafrodita é unicamente objeto de curiosidade e burla, assim como o psicopata sexual o é de desprezo e desconsideração. O primeiro é um ser monstruoso, um fenômeno com certa comicidade; o segundo é um detestável vicioso." Carlos Lagos GARCíA, 1925, p. 555.

Talvez um dos grupos sociais que atualmente mais causem repulsa, medo, ódio e, ao mesmo tempo, curiosidade, espanto e desejo seja o das pessoas que transitam entre os

Copyright () 2012 by Revista Estudos Feministas. 
gêneros e/ou sexos. Herdeiro de um imaginário tão antigo quanto persistente que mescla discursos vindos da religião à criminologia, da medicina à política, o discurso da monstruosidade, com toda sua imprecisão conceitual, parece ser um dos elementos organizadores desta discussão. Assim, o objetivo deste artigo é discutir a categoria "monstro" e sua íntima relação com a patologização e/ou criminalização de determinadas pessoas vistas como 'desviantes sexuais', em especial travestis, transexuais e intersexuais.

\section{O abjeto: categoria, além das categorias ou adjetivo?}

Nos últimos anos, em vários trabalhos científicos sobre sexualidade na área das ciências humanas, o termo "abjeto" tem sido bastante utilizado, especialmente no Brasil. Inspirada nos textos da filósofa norte-americana Judith Butler, que, por sua vez, retirou a noção de abjeto do livro The Powers of Horror, da psicanalista e filósofa búlgaro-francesa Julia Kristeva, essa palavra tem sido comumente empregada como um adjetivo, sinônimo de algo repulsivo, repugnante, desprezível, vil, que inspira horror. Em seus escritos, Butler usa com parcimônia a noção de abjeto, mas se pode seguir uma linha constante em suas análises: o abjeto é o que, na constituição do sujeito socialmente inteligível, é colocado 'de fora' desse sujeito, tornando-se seu exterior constitutivo.

Em Gender Trouble, de 1990, em sua breve discussão sobre o abjeto, referindo-se ao livro de Kristeva, Butler afirma:

O "abjeto" designa aquilo que foi expelido do corpo, descartado como excremento, tornado literalmente "Outro". Parece uma expulsão de elementos estranhos, mas é precisamente através dessa expulsão que o estranho se estabelece. A construção do "não eu" como abjeto estabelece as fronteiras do corpo, que são também os primeiros contornos do sujeito.'

Em Bodies that Matter (1993), em nota de rodapé, explica:

A abjeção (em latim, ab-jectio) implica literalmente a ação de jogar fora, descartar, excluir e, portanto, supõe e produz um terreno de ação desde o qual se estabelece a diferença. [...] Enquanto a noção psicanalítica de Verwerfung traduzida como "forclusão" produz a socialidade através do repúdio de um significante primário que produz um inconsciente ou, na teoria lacaniana, o registro de real, a noção de abjeção designa uma condição degradada ou excluída dentro dos termos da socialidade. [...] O que sustento é que, dentro da socialidade, existem certas zonas abjetas que também sugerem esta ameaça e que constituem zonas inabitáveis que o sujeito, em sua fantasia, supõe ameaçadoras para sua própria integridade, pois lhe apresentam a perspectiva de uma dissolução psicótica. ${ }^{2}$

Sem entrar na discussão psicanalítica, pode-se afirmar que o abjeto é o ininteligível, aquilo que, na constituição do sujeito (individual ou social), é expulso como não categorizável. O abjeto é que está fora das categorias de pensamento socialmente inteligíveis. Nesse sentido, nos limites deste artigo, abjeto é uma categoria de linguagem ${ }^{3}$ que denomina a falta de categorias de pensamento, ou seja, aquilo que fica de fora, expulso das categorias de pensamento socialmente criadas, estabelecidas e culturalmente inteligíveis em determinado período histórico.

' Judith BUTLER, 2003, p. 190.

2 BUTLER, 2008, p. 19.

${ }^{3}$ Esta é uma simplificação metodológica de minha parte visando a uma elhor compreensão dessas categorias. No limite, toda categoria de linguagem é ambém uma categoria de pensamento. 
Ainda acompanhando Butler, nas reflexões sobre sexo, gênero e sexualidade, os sujeitos abjetos, ou seja, aqueles que não se enquadram nas categorias conhecidas, não seguem aquilo que a autora chama de "gêneros inteligíveis", que "são aqueles que, em certo sentido, instituem e mantêm relações de coerência e continuidade entre sexo, gênero, prática sexual e desejo". ${ }^{4}$ Assim, os 'gêneros inteligíveis', que funcionam predominantemente ainda hoje, se organizam segundo a lógica do 'tem pênis, logo é homem, masculino e deve sentir atração afetivo-sexual por mulheres (é heterossexual)', e 'tem vagina, logo é mulher, feminina e deve sentir atração afetivo-sexual por homens'. Nesse campo, tanto pessoas homossexuais, bissexuais, quanto intersexuais, travestis, transexuais e todas aquelas que quebram essa pressuposta continuidade podem ser consideradas abjetas.

Creio que considerar essas pessoas como abjetas só seja possível quando o termo "abjeto", como já dito anteriormente, é usado como sinônimo de desprezível, repulsivo, vil, horrível, incompreensível. Talvez a maneira violenta e inferiorizante, com tonalidades de nojo, zombaria e medo com que essas pessoas são ainda cotidianamente tratadas, revele que essas pessoas não estão além ou fora das categorias conhecidas de inteligibilidade social. Talvez elas estejam em uma outra e específica categoria de inteligibilidade. Uma categoria organizada desde, pelo menos, a Antiguidade Clássica e que legitima a maneira com que elas são percebidas e tratadas socialmente: essas pessoas estão na categoria de "monstros".

\section{Monstro como uma categoria de inteligibilidade}

Conforme vários autores que trabalham o tema, ${ }^{5} \mathrm{o}$ 'monstro' é, por excelência, a marca hiperbólica de algo fora da ordem, seja ela 'natural', 'sobrenatural' ou, no mínimo, fora dos ordenamentos conhecidos. Ele apresenta 'outra ordem' do real ou, muitas vezes, um sinal, um aviso enviado pelo universo mágico para alertar contra possíveis 'desvios'. Constantemente, a monstruosidade é entendida como uma transgressão das leis estabelecidas, visando, através de sua presença, inspirar temores e dúvidas ou punir contra infrações.

O termo "monstro" parece não possuir uma origem muito clara. Para Rosemarie Garland Thomson, ${ }^{6}$ tal palavra vem do latim monstra e significa "mostrar, apresentar". Jeffrey J. Cohen" afirma que monstro deriva do latim monstrum, com significado de "aquele que revela, aquele que adverte". Também originando da língua latina, Claude Kappler ${ }^{8}$ informa que a essência de tal palavra estaria na raiz men, que indica os movimentos mentais. Dela surgiram as famílias de termos como monere, com o sentido de advertência divina, que com o tempo originou primeiro monistrum e depois monstrum e monstrare. José Gil conclui que monstro originou da palavra monstrare e que essa possui a ideia de "ensinar um comportamento, prescrever a via a seguir". 9

O monstro então é aquele que 'mostra' algo: uma revelação divina, a ira de Deus, as infinitas e misteriosas possibilidades da natureza, aquilo que o homem pode vir a ser, as bordas entre o humano e o inumano. É, portanto, a manifestação de algo fora do comum ou

${ }^{4}$ BUTLER, 2003, p. 38

5 Jeffrey Jerome COHEN, 2000; Claude APPLER, 1994; Rosemarie Garland THOMSON, 1996; e leda TUCHERMAN 1999.

${ }^{6}$ THOMSON, 1996, p. 3.

7 COHEN, 2000, p. 27.

${ }^{8}$ KAPPLER, 1994, p. 334

9 José GIL citado por TUCHERMAN, 1999, p. 103. 
esperado. Antes de tudo, o monstro representa uma categoria de pensamento, uma tentativa inteligível de classificar e orientar condutas em relação àqueles seres e pessoas que a princípio escapam da inteligibilidade cultural do período.

Conforme Kappler, ${ }^{10}$ em seu importante livro sobre o tema, os monstros vivem nos limites: no limite do saber, no limite do humano, nos limites das terras conhecidas e socialmente reconhecidas (ilhas, fundo dos mares, países estranhos, regiões exóticas, 'periferias' e 'favelas'). Mas talvez o mais importante é que o monstro vive nos limites das categorias: humano, animal, vegetal, mineral, anjo, demônio, homem, mulher, homo, hétero, bissexual, conhecido, desconhecido. A monstruosidade é a infinita e possível mixagem, união e ou borramento entre as categorias socioculturais.

E é por isso que o monstro não é o abjeto: "monstro" é uma categoria que opera no limite das categorias, no extremo entre as categorias, entre inclusive, talvez, a categorização e a não categorização. Mas, ainda assim, é uma categoria de reconhecimento social; ela é inteligível socialmente. Operando através dessa categoria, a violência, o sarcasmo, o nojo, o medo e a desqualificação não são simples reações ao desconhecido ou ao receio de perder uma pressuposta estabilidade ou ordem psicológica/individual ou social/coletiva, são atitudes cultural e historicamente legitimadas para se relacionar com quem não é compreendido como humano (no pior dos casos) ou é compreendido como sub-humano ou quase humano (no melhor dos casos).

Conforme Butler, "a nomeação é, ao mesmo tempo, o estabelecimento de uma fronteira e também a inculcação repetida de uma norma". " $\mathrm{E}$, talvez, por isso a noção de um lugar, de um locus específico onde habita o monstro seja fundamental: a categoria "monstro" é a região que dá forma e limite ao humano, sendo seu oposto constitutivo, mas na qual a noção de humanidade não opera com a mesma força ou com os mesmos pressupostos, ou seja, as mesmas regras que valem (e são reforçadas) para o mundo dos humanos não são vistas como válidas para o universo dos monstros.

Historicizando o conceito de monstro, percebemos que não é apenas terror que a figura monstruosa provoca, é também fascínio, encanto, dúvida, fonte de curiosidade e desejo: "o monstro é transgressivo, demasiadamente sexual, perversamente erótico, um fora-da-lei". ${ }^{12}$ Nesse sentido, talvez o monstro tenha em demasia algo que o abjeto tenha de menos: o fascínio pela quebra das normas conhecidas, o encanto pela transgressão, a sedução pelo quase desconhecido, a curiosidade pela inteligibilidade.

Por isso, desde a Antiguidade até pelo menos o século XVI, os monstros no Ocidente também eram classificados entre as "maravilhas" ou os "prodígios" do mundo e podiam evocar tanto o medo quanto a simpatia e a risada através de suas formas exageradas, assustadoras ou ridículas. Ainda para Claude Kapller, é graças à 'malignidade' encontrada em muitos dos entes fantásticos importados do Oriente, principalmente da China, a partir do século XIII, que vai ocorrer uma mudança fundamental na noção de monstro. $O$ cristianismo já possuía a tendência de associar as deformidades e a feiúra ao diabo. Mas se até esse período ele era visto como tendendo mais para o ridículo do que para o maligno, a partir daquela data começa uma sutil, mas constante, e resistente ideia de que as 'maravilhas' não são tão ambíguas e engraçadas como se supunha, mas essencialmente maléficas e perigosas. É somente a partir da baixa ldade Média, com a associação do conceito de monstro com a figura do demônio, que o primeiro passa a ser entendido apenas como a encarnação de algo destrutivo por natureza, perdendo qualquer outra

10 KAPPLER, 1994.

$"$ BUTLER, 2000, p. 161.

${ }^{12}$ COHEN, 2000, p. 48.

562 Estudos Feministas, Florianópolis, 20(2): 559-568, maio-agosto/2012 
face que não a do ódio ao gênero humano. ${ }^{13} \mathrm{~A}$ partir desse período, com a dominação da ideologia cristã na Europa, a estranheza do 'bizarro' vai ser substituída em grande parte pelo medo do maligno.

É esse temor historicamente criado pelo monstro que vai justificar a maneira socialmente reconhecida de lidar com ele: de um lado, o ódio e a violência, de outro, o descaso, a humilhação e o escárnio. Talvez não conheçamos uma maneira de enfrentar a ameaça que a não categorização (o abjeto) represente. Mas nossa cultura criou uma forma específica de tratar com as pessoas que se encaixam na categoria de monstros: ao encará-las como o equivalente ao Mal e ao caos, a única ação ou reação socialmente inteligível é a destruição ou o anulamento (literais ou simbólicos) dessas pessoas. O monstro não é apenas uma domesticação do abjeto, mas sua organização como uma categoria específica que legitima tanto a atração quanto a destruição ou punição do sujeito sobre o qual recai essa mesma atração.

Ora, talvez mais antiga que a associação da monstruosidade com o mal seja a associação dessa com o universo erótico/sexual: "O monstro corporifica aquelas práticas sexuais que não devem ser exercidas ou que devem ser exercidas apenas por meio do corpo do monstro". ${ }^{14}$ Mas se essa relação vem desde a Antiguidade, ${ }^{15}$ é apenas no século $\mathrm{XIX}$, com o surgimento da ciência sexual, ${ }^{16}$ que ela tornar-se-á patologizada, através do discurso científico racionalizado e pretensamente universal.

Não por acaso, a associação entre a monstruosidade, as sexualidades e os sexos/ gêneros ininteligíveis (chamados de perversos, pervertidos, parafílicos ou anormais) é uma constante nos escritos médicos ou jurídicos sobre o tema, desde principalmente a segunda parte do século XIX até o final da primeira metade do XX.

A clássica obra de Krafft-Ebing, ${ }^{17}$ Psychopatia Sexualis, pode ser vista como o maior compêndio de monstros - no caso, 'monstros sexuais' - já criado em nossa história, tendo ele usado esse próprio termo algumas vezes. Inaugurando uma nova taxonomia, a obra desse psiquiatra também é uma continuidade da tradição ocidental de classificar prodígios, monstros e 'aberrações' entre os seres que 'violam' alguma ordem: divina, natural, biopsicológica ou social.

Conforme o médico e sociólogo Georges Lanteri-Laura, ${ }^{18}$ em seu livro Leitura das perversões, os 'desviantes sexuais' são divididos pela psiquiatria desse período em duas categorias: os 'bons' e os 'maus'. Para esse discurso, entre os primeiros estão as pessoas respeitadas por seus bens, capacidades intelectuais e um sobrenome socialmente reconhecido. Eles são objetos de compaixão, compreendidos como infelizes sobre os quais um destino trágico se abateu com males muitas vezes de origem biológica e congênita. Para tais indivíduos, são desenvolvidos todos os esforços médicos e jurídicos visando curálos ou livrá-los das prisões. Os centros de reabilitação, as termas e os balneários contavam com esse público. Esses são os perversos, pessoas compreendidas como doentes.

Já os segundos, sem posses, considerados astuciosos, mas não inteligentes, e cuja imagem é quase sinônimo de marginalidade, são encarados com rigor, receio e desprezo. A ciência considera-os mais próximos do vício que da doença, e as faltas por eles cometidas declaram de antemão a condição de culpados, pois acumulam 'desvios' com uma vida dita 'desregrada' ou trazem na carne os estigmas da degeneração hereditária, fruto de

\footnotetext{
${ }^{13}$ KAPPLER, 1994.

14 COHEN, 2000, p. 44

${ }^{15}$ COHEN, 2000; KAPLER, 1994; e TUCHERMAN, 1999.

16 FOUCAULT, 1988.

17 Richard Von KRAFFT-EBING, 1998

${ }^{18}$ Georges LANTERI-LAURA, 1994.
} 
pais também envolvidos em 'excessos' de toda ordem. Para eles, os manicômios judiciários, as prisões e a psiquiatria forense. Esses são os pervertidos, entendidos antes de tudo como criminosos.

Assim, a perversão delineia-se como uma doença e a perversidade, como um vício ou crime. Ainda para Lanteri-Laura, os tais 'perversos' ou 'pervertidos' são vistos pelos médicos e pelas nascentes ciências da psique ora como ridículos, ora como monstros. O importante a ressaltar nesse caso é que novamente um jogo de oposições é evocado, dividindo os tais sujeitos em vítimas (doentes) e malfeitores (criminosos). Segundo esse autor,

daí resultou, no final das contas, a separação entre os bons e os maus perversos, e a psiquiatria leiga se afigura, sem grande respeito humano, uma espécie de juízo final médico, onde à esquerda eram dispostos os bodes expiatórios e, à direita, as ovelhas. Os maus perversos foram mostrados como monstros [...] inversamente, os bons perversos mostravam-se atormentados, infelizes, incompreendidos, cheios de hesitação antes e petrificados de remorso depois, vivendo na angústia e no deleite melancólico, desgostosos com eles mesmos e muito distantes do gozo [...]. Estruturou-se, por conseguinte, um campo das perversões em que a medicina, no tocante a uns, denunciava rapidamente o perigo social, e, no tocante a outros, pretendia ser mais compreensiva que a justiça: somente o especialista acreditava possuir o saber que permitia efetuar essas distinções. ${ }^{19}$

A figura do monstro, ao ser interiorizada, será uma das bases sobre a qual as ciências da psique construirão a figura dos anormais, dos perversos e dos pervertidos, pois, segundo Michel Foucault, "o anormal [...] é no fundo um monstro cotidiano, um monstro banalizado. O anormal vai continuar sendo, por muito tempo ainda, algo como um monstro pálido". ${ }^{20}$

Ainda no início do século XX, encontramos a associação explícita entre monstros e 'desviantes sexuais', por exemplo, tanto na nascente psicanálise como entre os médicoscirurgiões. Na conferência sobre A vida sexual dos seres humanos (1917), Freud deixa clara a separação entre os humanos 'normais' e os monstros 'patológicos':

Agora, porém, chegamos a uma longa série de pessoas anormais cuja atividade sexual diverge cada vez mais amplamente daquilo que parece desejável para uma pessoa racional. Na sua multiplicidade e estranheza, somente podem ser comparadas aos monstros grotescos [...] podemos, nos detalhes mais visíveis assim como nos mais sutis, determinar os pontos em que essas anormalidades se baseiam naquilo que é normal e os pontos em que divergem da normalidade. E os senhores não podem deixar de perceber que, aqui, mais uma vez, aquilo que se refere à atividade sexual tem essa característica de impropriedade, embora aqui, na sua maior parte, isto se intensifique ao ponto de ser abominável. ${ }^{21}$

Já o cirurgião argentino Carlos Lagos García, ao descrever casos de intersexualidade, afirma em 1925

O delito de infração às leis da morfologia sexual impostas à grande maioria do gênero humano, como todo ato delituoso, está sujeito a graduações [...] podem ser esses pecados que vão da simples e mais ou menos desapercebida anomalia, até a complexa e ruidosa monstruosidade.

\footnotetext{
19 LANTERI-LAURA, 1994, p. 45.

${ }^{20}$ FOUCAULT, 2001, p. 71.

${ }^{21}$ Sigmund FREUD, 1999.

${ }^{22}$ Carlos Lagos GARCÍA, 1925, p. 19.
}

564 Estudos Feministas, Florianópolis, 20(2): 559-568, maio-agosto/2012 
Dentro da nascente ciência sexual, todos aqueles que não se encaixavam no padrão de uma vida sexual heterossexual, monogâmica e com fins procriativos eram vistos como potencialmente monstruosos. ${ }^{23} \mathrm{Um}$ exemplo explícito dessa concepção são as pessoas que confundem, misturam ou transitam entre os sexos e os gêneros, descendentes diretas do grande monstro sexual por excelência do Ocidente: o hermafrodita.

Questionando e subvertendo os limites estabelecidos entre homem e mulher, masculino e feminino, homo e heterossexualidade, surge no século XIX a figura clínica do pseudo-hermafrodita, longe dos deuses e do universo mágico e divino; filho da modernidade, da medicina e da ciência sexual. Não mais um prodígio da natureza, mas um 'desvio' dessa. Passa-se agora a buscar o 'verdadeiro sexo' que irá definir quem é homem e quem é mulher, sem os 'perigosos' riscos de interpretações equivocadas. Dessa forma, a ambiguidade sexual não perde lugar, mas é principalmente interiorizada. Nasce assim o 'hermafrodita psíquico'. Dele irão se originar todos os tais perversos e pervertidos sexuais e, principalmente, as identidades (para uns) e/ou patologias (para outros), criadas no século $\mathrm{XX}$, de travestis, transexuais e intersexuais, ou seja, todas essas classificações já se originaram da concepção de certo tipo de monstro. E o que importa não é a busca pela origem 'verdadeira' ou a legitimidade da filiação, mas perceber o quanto a ideia de um perigo pressuposto (e de uma reação violenta legítima contra esse perigo) é constitutiva dessas próprias categorias científicas.

Não é por acaso que esse novo monstro sexual, o pseudo-hermafrodita da ciência, ressoando os ecos de seu ancestral, o hermafrodita mítico-religioso, estará intimamente imbricado no desenvolvimento da ciência sexual, configurando-se, ela mesma, desde seu início, como um pêndulo que compreende os sexos/gêneros ininteligíveis ora como crime, ora como doença. Conforme Foucault, ao analisar a figura monstruosa na Idade Média,

o que faz com que o monstro humano seja um monstro, não é somente a exceção em relação à forma da espécie, é a perturbação que traz às regularidades jurídicas (quer se trate das leis do casamento, dos cânones do batismo ou das regras de sucessão). ${ }^{24}$

Essa íntima associação entre a monstruosidade, a doença e o crime, como vimos, é bem antiga e constituidora da noção de 'desvio' sexual, pois, novamente citando Foucault, "enquanto, antes, 'a monstruosidade trazia em si um indício de criminalidade', agora há 'uma suspeita sistemática de monstruosidade no fundo da criminalidade'”. ${ }^{25}$ Ora, essa relação não desaparece, mas é redimensionada pelo viés científico da psicobiomedicina, como demonstra o já citado Lagos García, em seu livro Las deformidades de la sexualidad humana:

Os disformes sexuais humanos resultam verdadeiras exceções que não cabem dentro das regras da morfologia sexual [...] assim como os delinqüentes comuns estão em luta, por seus atos, com as leis estabelecidas pela sociedade, assim também os disformes sexuais somáticos chocam, por suas formas, com as leis da configuração sexual. ${ }^{26}$

\footnotetext{
${ }^{23}$ Claro que nem toda ciência sexual estigmatizava aqueles que não se encaixavam nos sexos/gêneros inteligíveis. Exemplos dessa postura são Magnus Hirschfeld e Havellock Ellis. Mas, no todo, eles foram a exceccão, não a regra. Não fosse isso, o movimento sociopolítico dos homossexuais teria se apoiado totalmente na ciência, e não a enfrentado na sua luta por direitos. Da mesma forma, várias práticas e desejos sexuais, identidades de gênero e configurações corporais não estariam até hoje na Classificação Internacional de Doenças (CID-10) ou no Manual Diagnóstico e Estatístico de Transtornos Mentais (DSM-IV). Ver Berenice BENTO e Larissa PELÚCIO, neste dossiê.

${ }_{24}$ FOUCAULT, 1997, p. 61.

${ }^{25}$ FOUCAULT, 2001, p. 432

26 GARCÍA, 1925, p. 17
} 
Dessa forma, percebemos como a inteligibilidade desenvolvida por nossa ciência sexual foi forjada em cima dos binômios saúde/doença, lei/crime, muitas vezes se constituindo no campo mesmo de intersecção entre esses extremos. Não foi por acaso que, em grande parte do Ocidente, desde o século XIX, as lutas sociais e políticas pela descriminalização de algumas sexualidades vistas como desviantes, embora vitoriosas juridicamente, redundaram na patologização (direta ou indireta) dessas mesmas sexualidades. Assim foi com a homossexualidade, que, de crime no século XIX, passou a ser doença na primeira metade do $X X$ e, depois desse período, quando não é mais oficialmente reconhecida como crime nem como doença, é pulverizada e redimensionada em uma série de novos 'transtornos', tais como a homossexualidade egodistônica e o próprio transtorno de identidade de gênero, estando sua inteligibilidade social ainda fragilizada e não totalmente livre de estigmas.

Ao ser considerada parafílica, perversa, transtornada, psicótica ou possuidora de distúrbios e anomalias, a completa humanidade de travestis, transexuais e intersexuais já é questionada e posta em xeque, pois todas essas classificações já pressupõem um 'desvio' de algo sadio e 'normal' - o humano -, restando como meio habitável e inteligível para elas a categoria dos monstros. Inclusive, a própria patologização dos sexos/gêneros pode ser compreendida como uma forma 'humanizada' de punição por algum tipo de transgressão criminosa. O que causa a agressiva reação com que essas pessoas são tratadas não é o fato de elas se apresentarem como 'mulher de verdade', 'homem vestido de mulher' ou qualquer coisa do tipo, mas o fato de já serem compreendidas dentro de uma categoria (científica, religiosa ou jurídica) de desvio, de 'monstruosidade' que legitima e autoriza a violência contra elas.

Ora, a busca pelo reconhecimento social dos 'desviantes', no caso específico deste artigo, de travestis, transexuais e intersexuais, passa justamente por criar um novo campo de inteligibilidade dessas pessoas que escape do estigma crime/doença. Mais do que conquistar direitos civis através de políticas públicas, a luta dessas pessoas é para saírem da categoria de monstros e conseguirem habitar integral e legitimamente a categoria "humanos". E, para isso, é fundamental a despatologização da travestilidade, da transexualidade, da intersexualidade e de demais possibilidades de cruzamentos entre sexos e gêneros. ${ }^{27}$

\section{Além do crime, da doença e/ou da "normalidade" existe o quê? Transitar para onde?}

Mas, se como vimos, a lógica que estrutura a compreensão sobre os 'desviantes' na ciência sexual é operar com o binômio doença/crime, ao conseguir se desvencilhar da associação com a doença - ou seja, se as identidades 'transgêneras' ${ }^{28}$ não forem mais oficialmente consideradas transtornos, parafilias, perversões ou anomalias -, para qual campo de inteligibilidade elas migrarão? Voltarão ao do crime?

Como demonstrou Gilles Deleuze,,$^{29}$ vivemos numa sociedade de controle. Ela não funciona mais apenas pela lógica da disciplina, que pressupunha a criminalização de alguns e seu encarceramento por outros. Na sociedade de controle, seguimos a lógica da

\footnotetext{
${ }^{27}$ Como a campanha internacional Stop Trans Pathologization. Mais nformações no site < http:// www.stp2012.info/old/pt>. Ver também neste dossiê o texto de Berenice Bento e Larissa Pelúcio "Despatologização do gênero: a politização das identidades abjetas".

${ }^{28}$ Aqui entendidas como travestis, transexuais, cross-dressers, intersexuais e todas as pessoas que transitam entre os sexos e os gêneros.

${ }^{29}$ Gilles DELEUZE, 1992a e 1992b.
}

566 Estudos Feministas, Florianópolis, 20(2): 559-568, maio-agosto/2012 
segurança: todos somos criminosos em potencial e o trabalho de vigilância social é cobrado de todos, indo desde a denúncia anônima de crimes ao monitoramento pessoal e 'livre' das redes sociais digitais, sendo isso chamado de 'cidadania'. O medo torna-se a chave central da legitimidade política ${ }^{30}$ e a indústria da segurança, o mercado que mais cresce ${ }^{31}$ e angaria capital: econômico, social e simbólico. De um lado ou de outro da cela, esperase que nos tornemos todos carcereiros.

Não acredito que o retrocesso legal de criminalizar práticas ou identidades sexuais vistas atualmente como não perigosas ${ }^{32}$ possa ocorrer - embora o crescente fundamentalismo religioso mostre que isso não é impossível -, mas a questão é: se essas pessoas estão categorizadas no campo dos monstros sexuais, e esses só são inteligíveis ora como criminosos, ora como doentes, como torná-las inteligíveis fora desses limites? Como escapar desse movimento pendular? Será que a inclusão dessas pessoas na lógica da segurança médica da sociedade de controle, tornando-as, por exemplo, 'agentes de prevenção', é capaz de fazê-las transitar da categoria de monstros para a de humanos ou apenas reforça a estigmatização dessas através da íntima relação simbólica, novamente, com a doença?

Com certeza os direitos sociais são imprescindíveis para essa mudança, assim como a despatologização. Mas creio que, antes de tudo, necessitamos não apenas retirar determinados seres da categoria de monstros e alocá-los no campo dos "humanos", necessitamos repensar os limites da própria categoria "humano", remodelando assim o que fica em seu exterior incategorizável (o abjeto) e, principalmente, desenvolver uma nova postura com relação ao que classificamos como monstro. Não apenas acabar com a categoria "monstro" (pois isso seria o equivalente, no plano conceitual, ao extermínio total dos monstros), mas retirar a lógica da violência e da agressão legítimas dentro dessa categoria. Nosso medo e ódio aos monstros foram criados historicamente. Da mesma forma, podem ser revertidos.

Em uma época em que universidades, empresas e hospitais demitem professores, funcionários e médicos, e contratam seguranças que vigiam e controlam não apenas propriedades e instituições, mas também, no limite, em sua função simbólica, vigiam categorias de pensamento, gerenciando a manutenção do medo e da insegurança social, como se deslocar da monstruosidade, do crime ou doença? Ou seja, para onde transitam as identidades 'trans'?

\section{Referências}

BUTLER, Judith. "Corpos que pesam: sobre os limites discursivos do 'sexo'”. In: LOURO, Guacira Lopes (Org.). O corpo educado: pedagogias da sexualidade. Belo Horizonte: Autêntica, 2000.

Problemas de gênero: feminismo e subversão da identidade. Rio de Janeiro: Civilização Brasileira, 2003.

Deshacer el gênero. Barcelona: Paidós, 2006.

Cuerpos que importan. Buenos Aires: Paidós, 2008.

$\overline{\mathrm{COHEN}}$, Jeffrey Jerome. "A cultura dos monstros: sete teses". In: SILVA, Tomaz Tadeu da (Org.). Pedagogia dos monstros. Belo Horizonte: Autêntica, 2000. p. 23-60.

\footnotetext{
30 Barry GLASSNER, 2003.

31 NaOmi KLEIN, 2008; e Loïc WACQUANT, 2001.

32 O que não é o caso da pedofilia. Pode-se afirmar inclusive que o pedófilo é, atualmente, o grande monstro sexual, constituindo sua monstruosidade justamente na confusa união entre o crime e a doença, tornado-se ele um criminoso e doente ao mesmo tempo.
} 
DELEUZE, Gilles. "Post-scriptum sobre as sociedades de controle". In: Rio de Janeiro: Editora 34, 1992a. p. 219-226.

Conversações.

. "Controle e devir". In: Conversações. Rio de Janeiro: Editora 34, 1992b. p. 209-218

FOUCAULT, Michel. História da sexualidade I: a vontade de saber. Rio de Janeiro: Graal, 1988.

Resumo dos cursos do Collège de France. Rio de Janeiro: Jorge Zahar Editor, 1997.

Os anormais. São Paulo: Martins Fontes, 2001.

FREUD, Sigmund. Conferência XX: A vida sexual dos seres humanos. Rio de Janeiro: Imago, 1999.

GARCÍA, Carlos Lagos. Las deformidades de la sexualidad humana. Buenos Aires: El Ateneo, 1925.

GLASSNER, Barry. Cultura do medo. São Paulo: Francis, 2003.

GRUNVALD, Vitor. "Butler, a abjeção e seu esgotamento". In: DÍAZ-BENÍTEZ, Maria Elvira; FíGARI, Carlos Eduardo (Org.). Prazeres dissidentes. Rio de Janeiro: Garamond, 2009. p. 31-68.

KAPPLER, Claude. Monstros, demônios e encantamentos no fim da ldade Média. São Paulo: Martins Fontes, 1994.

KLEIN, Naomi. A doutrina do choque. Rio de Janeiro: Nova Fronteira, 2008.

KRAFFT-EBING, Richard Von. Psychopatia Sexualis. Nova York: Arcade Publishing, 1998.

LANTERI-LAURA, Georges. Leitura das perversões. Rio de Janeiro: Jorge Zahar, 1994.

PELÚClO, Larissa. Abjeção e desejo. São Paulo: Annablume, 2009.

PELÚCIO, Larissa; MISKOLCI, Richard. "A prevenção do desvio: o dispositivo da aids e a repatologização das sexualidades dissidentes". Sexualidad, Salud y Sociedad, n. 1, p. 125-157, 2009.

STOP TRANS PATHOLOGIZATION. Disponível em: <http://www.stp2012.info/old/pt> . Acesso em: 10 mar. 2011.

THOMSON, Rosemarie Garland. "From Wonder to Error: A Genealogy of Freak Discourse in Modernity." In: (Org.). Freakery: Cultural Spetacles of the Extraordinary Body. New York: New York University Press, 1996. p. 1-19.

TUCHERMAN, leda. Breve história do corpo e de seus monstros. Lisboa: Vega, 1999.

WACQUANT, Loïc. As prisões da miséria. Rio de Janeiro: Jorge Zahar Editor, 2001.

\begin{abstract}
Transit to Where? Monstrosity, (Des)pathologization, Social Insecurity and Transgender Identities

Abstract: The aim of this paper is to discuss the category of "monster" and its close relation with the pathologization and criminalization of people seen as "sexual deviants", especially transvestites, transsexuals and intersex. At the beginning of the XXI century, with the questioning of medical authority, the politicization of the social movements of transvestites and transsexuals and their battle for despathologization, where to direct the "disorders" of sex or gender, "paraphilias"' and "perversions" with all the persistent stigma attached to them? Will they be understood again as potentially dangerous by the increasingly widespread culture of security?

Key Words: Monster; Abject; Transvestites; Transsexuals; Sexual Science.
\end{abstract}

568 Estudos Feministas, Florianópolis, 20(2): 559-568, maio-agosto/2012 